\title{
Towards a hydrogen economy - a sustainable pathway for global energy transition
}

\author{
Jeffrey Kwok
}

\begin{abstract}
Hydrogen is receiving increasing attention for achieving carbon abatement in various sectors, including transport, logistics, thermal engineering and industrial feedstock, etc. Hydrogen can also support distributed power supply that raises national energy security. Both commercial and industrial sectors share a common vision that increasing the cost-effectiveness of renewable hydrogen represents their strategic achievement towards substantial sustainability. This paper explains how hydrogen can play seven roles in the energy transition which include large-scale integration of renewable energy into the power grid, medium for storing and distributing energy across sectors and/or regions, a buffer to increase the electric system resilience and clean fuel for fuel cell vehicles to decarbonise transport. Besides, hydrogen can decarbonise building energy consumption and serve as feedstock using captured carbon. Power Assets Holdings Limited (PAH), a global investor in energy and utility-related business, has identified a hydrogen economy as a strategic vision in its business plan for zero carbon readiness in 2035 and a carbon-free business model in 2050. In this paper, the features and attributes of different hydrogen projects, such as H21 and InTEGRel in the UK and Hydrogen Park in South Australia, are discussed to demonstrate the commercial deployment of hydrogen power.
\end{abstract}

KEYWORDS Hydrogen; energy transition; de-carbonise; H21; HyP SA

CONTACT Jeffrey Kwok@jkwok@powerassets.com

Received 22 November 2020

\section{Introduction}

At the 2015 United Nations Climate Change Conference, COP 21 held in Paris, 195 countries signed an agreement to set a goal of limiting global warming to "well below $2{ }^{\circ} \mathrm{C}$ " compared with pre-industrial levels (Nieto et al., 2018). A two-degree warming scenario requires deep cuts in emissions, as much as 70 percent by 2050 (Environmental and Energy Study Institute, 2015). Many countries believe that green hydrogen produced by renewable energy can be a major alternative energy source to reduce the required carbon emission (Stern, 2018).

This paper describes the various roles hydrogen can play in the energy transition, the hydrogen road map of major countries, and the various initiatives on hydrogen that the group companies of Power Assets are taking.

\section{Hydrogen can play seven roles in the energy transition}

Besides the power industry, other sectors such as transport, residential and public heating, industry, and agriculture are major carbon emitters. This means that even if all power is generated from renewable energy, it can only cut about $25 \%$ of the total emission (United States Environmental Protection Agency, n.d.). Other sectors need to take necessary actions as well.

Green hydrogen utilising renewable energy as a power source and blue hydrogen which capture and store the greenhouse gases produced during the manufacturing process can be taken as an alternate energy source replacing fossil fuels. It is because hydrogen is a carbon-free, safe and multipurpose energy carrier that burns without any harmful emission which can be used as fuel for power and heat or in the industry as feedstock (Wang et al., 2019). Hydrogen has a high energy density (almost three times more than diesel or gasoline) which is easily usable like oil and gas and can also be directly converted into electricity by fuel cells with both processes not emitting any carbon. Hydrogen can be stored and transported in high pressure gaseous, liquid (liquefied hydrogen or ammonia), or even hydride-based solid form.

Hydrogen can play the following seven roles in the energy transition covering all sectors:

\subsection{Enabling large-scale renewable integration and power generation}

As more and more utility-scale renewable energy source such as wind and solar power plants are being built, it becomes difficult for a grid operator to control the electric system as the daily as well as seasonal electricity supply and demand are not matched resulting in frequent curtailments of renewable power wasting precious clean energy source and incur financial damage for project owners.

Hydrogen can be used to optimise the power system by utilising excess power supply from renewables to run electrolysers to generate green hydrogen and store it for future re-use in other areas (transport, industry and heating) (Mohammadi and Mehrpooya, 2018). Thus, it can safeguard renewable projects investment returns, improve power system stability, and also act as a medium to store clean energy and send it back to the grid when generation from the intermittent renewable power is low. 


\subsection{Distributing energy across sectors and regions}

While about $8 \%$ to $15 \%$ of power is lost through the transmission and distribution cables from the power plant to customers (The World Bank, 2018), there is almost no loss when transporting hydrogen. Hydrogen is therefore a higher efficient method for bulk transport of renewable energy over long distances by pipe, ship or truck. Countries with high renewable and/or fossil fuel resources are contemplating to produce green and/or blue hydrogen at remote locations and transport it to faraway load centres via high-pressure pipes, and even by vessel to high energy demand countries.

The use of the existing natural gas network to transport hydrogen is under test in Leeds in the UK, the first city that has planned to repurpose its existing gas network to distribute hydrogen by 2026 (Ogden et al., 2018).

\subsection{Acting as a buffer to increase the electric system resilience}

The frequency variation of an electric system is a result of power mismatches between supply and demand. As more and more renewable generation facilities are installed and connected to the grid, the chance of intermittent power supply and demand mismatch is getting higher and higher, making the power system more difficult to control or even at risk when a sudden massive loss of renewable resources occurs. The electricity grid and the gas network can be connected by means of hydrogen. While hydrogen is being produced with excess renewable energy supply, power can be sent back to the grid when the wind speed or solar irradiation is low or after sunset by using hydrogen to fuel the gas turbines. Hydrogen can therefore be used as a clean energy storage medium to cope with today's fast-changing energy supply and demand fluctuation and help stabilise the power grid. As hydrogen can be used for long-term bulk storage, and conveniently used for many applications, it is very suitable to be used as an energy buffer and storage reserve (Afgan and Veziroglu, 2012).

\subsection{Decarbonising transport}

Fuel cell electric vehicles (FCEV) have the following benefits in decarbonising the transport sector (Trencher, 2020). Firstly, the high energy to mass ratio of hydrogen allows FCEV to travel longer distances $(>500 \mathrm{~km})$ without refilling. Secondly, the refuelling time of FCEV can be completed within a few minutes (The Fuel Cells and Hydrogen Joint Undertaking, n.d.), which is in par with the time required for petrol /diesel cars. Thirdly, as hydrogen has a higher energy density resulting in much more energy that can be stored inside the fuel tank, FCEV is particularly suitable to take heavy load and travel long distances. Lastly, existing petrol stations and associate infrastructures can easily be converted to supply hydrogen to FCEV. FCEV will emerge in all sentiments from passenger cars, vans, buses, trucks, trams and non-electrified trains. In the marine and aviation sectors, synthetic fuels made out of hydrogen are under development.

\subsection{Decarbonising industry energy use}

Hydrogen has the advantage of being used to decarbonise industrial process heat as it is available as a by-product of chemical process and can provide uninterruptable power supply with fuel cell as well as heat (Serincan, 2016). When hydrogen is used to process heat and drying, it combusts with zero emission. Electric heating can be replaced by hydrogen burners to produce high-grade heat ( $>400$ Deg C). Those regions that have constraints in their energy system might prefer hydrogen instead of electricity for industrial energy use. Industry can also adopt a combination of hydrogen burners and fuel cells to fulfil its needs. Though fuel cells have higher efficiency than burners and can provide heat and power at the same time, it requires significant investment while burners just need adjustments of existing equipment such as nozzle tuning.

\subsection{Serving as feedstock using captured carbon}

Hydrogen is being used as a feedstock for refining and fertiliser and chemical production. Decarbonised hydrogen using carbon capture technology can be used as industry feedstock to replace fossil feedstock. It can substitute carbon as a reducing agent when manufacturing iron, and with $\mathrm{CO}_{2}$ to produce hydrocarbon-based chemicals, such as methanol and derived products. The Hydrogen Council forecast using decarbonised hydrogen in the production of feedstock can reduce annual $\mathrm{CO}_{2}$ emission by 440 million tons in 2050 .

\subsection{Helping decarbonise building heating}

Existing buildings using natural gas as fuel for heating can use hydrogen (either pure or blended with natural gas), as an alternate clean fuel to fully or partially decarbonising the gas grid. Other hydrogen technologies, such as fuel cell micro CHPs (combined heat and power system), have high efficiency for heat and power generation above $90 \%$. Hydrogen itself can serve as a fuel for those houses already connected to the gas grid. The conversion from natural gas to hydrogen combustion-based heating requires relatively small adjustments and investments and the customers can keep using the existing gas grid for a safe supply of hydrogen blended into natural gas, and ultimately for pure hydrogen.

\section{Hydrogen can be used safely}

Despite higher burning velocity, greater flashback tendency, lower limits of flammability and ignition energy than natural gas, hydrogen has been used for more than 
90 years in the industry with an excellent safety record in the area of production, storage, transport, and utilisation (Molkov, 2020). Hydrogen can be as safe as other fuels when sufficient safety standards, guidelines, and procedures have been established along its entire value chain and duly observed when handling it. Besides, the general public and customers should be well informed of hydrogen's characteristics.

\section{Important milestones can be reached in 2030}

- 10 - 15 million fuel-cell vehicles on the road, including cars, taxis, vans and light commercial vehicles (S\&P Global Platts, 2020);

- $\quad$ First large-scale high-grade heat projects using 3.5 Mt hydrogen (BW Businessworld, 2021); and

- Blending hydrogen into the existing natural gas network which is connected to 50 million households (BW Businessworld, 2021).

Several large-scale demonstration projects are proceeding. Offshore wind-to-hydrogen pilot plants are either in operation or under construction in Germany, Italy, Spain, UK, Netherlands, Denmark and the North Sea (Chrysochoidis-Antsos, 2020). In Germany, a 100-MW power-to-gas plant for sector coupling is planned to be connected to the grid in 2022 (Weidner et al., 2018). The North Sea Wind Power Hub has a plan to install 10,000 wind turbines for hydrogen production (Flynn, 2016).

In Belgium, France, Germany and the Netherlands, there are hydrogen networks for transporting excess hydrogen via the natural gas grid from one chemical plant to another plant and use it as feedstock (Quarton and Samsatli, 2020). In England, three salt caverns are used to store hydrogen. There are ongoing projects for assessing the potential for additional hydrogen storage in other salt caverns (Caglayan, 2020).

In the transport sector, there will be 5,000 hydrogen refuelling stations over the world by 2030 . The Chinese Government provided a total of RMB 85 bn subsidising fuel-cell-powered vehicles in 2018 alone ( $\mathrm{Gu}, 2020)$. Local governments have been trying to match the national subsidy standard. Many provinces and cities have plans to implement FCEVs and build hydrogen refuelling stations. In Guangdong Province, the first commercial fuel-cell tram line started operation in 2019 (Ballard Power System, 2019).

\section{Hydrogen projects that aim for a zero-carbon future}

Power Assets Holdings Limited joined the Hydrogen Council in 2019. The Hydrogen Council is a global CEOled initiative of leading companies that share a common vision and long-term ambition for hydrogen to facilitate the energy transition.

The Hydrogen Council engages policy makers, investors and NGOs in promoting the energy transition into hydrogen power. It strives to devise action plans and implement them to attract large-scale investments to accomplish the successful commercialisation of hydrogen power worldwide. The Hydrogen Council has executed many flagship projects all over the world. One of these projects is the UK H21 project participated by Northern Gas Networks, in which Power Assets holds a major stake.

\subsection{H21 Project}

In 2016, Northern Gas Networks, the gas distributor for the north of England, conducted the H21 Leeds City Gate feasibility study on decarbonisation. It concluded that full conversion from natural gas into hydrogen in the UK was technically sound and economically viable (Northern Gas Networks, 2020).

Based on the Leeds City Gate study results, the H21 North of England strategic report was produced in 2018 delivering a conceptual design to convert the gas networks in the north of England to transport hydrogen between 2028 and 2035.

H21 NIC (Network Innovation Competition) aims to provide quantitative safety evidence for the existing UK's gas distribution networks to fully convert themselves from supply natural gas to hydrogen gas (Figure 1). The projects are being carried out in phases:

Phase 1a-Background testing at the Health and Safety Laboratories, Buxton to evaluate the potential variation in background leakage levels.

Phase $1 \mathrm{~b}$-Consequence testing at the DNV/GL facility at RAF Spadeadam in Cumbria to determine the safety risk under the background condition, system failure and operational repair on a hydrogen gas network.

Phase 2 - Tests will be conducted to investigate the effectiveness of the operational procedures.

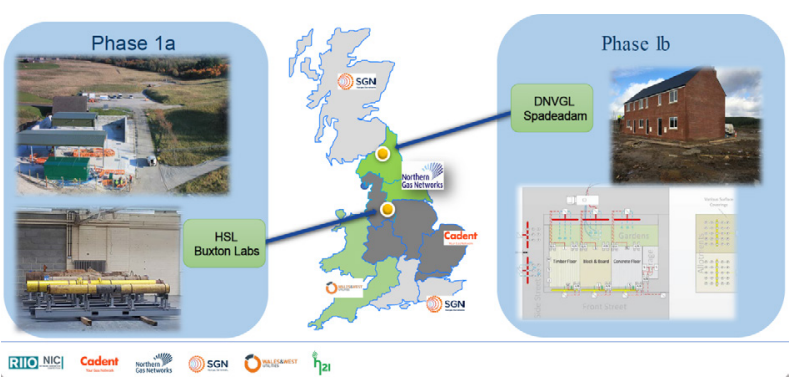

Figure 1. The H21 Workstreams: Phases 1a \& 1b. 


\subsection{InTEGRel - Integrated Transport Electricity Gas Research Laboratory}

It is the UK's first multi-vector industrial networks research centre with collaboration between Newcastle University's Centre for Energy System Integration, Northern Powergrid, and Northern Gas Networks (ITM Power, 2018). It aims to develop a world-leading emerging sector in Gas and Electricity Network integration with the following features (Figure 2):

(1) Customer Energy Village for testing of innovative solutions to energy challenges e.g. Hydrogen as a Heating Fuel, Low Carbon Heating

(2) Innovation Hub for engagement and skills development and training

(3) Energy Generation, Storage and CCS Zone

(4) Ultra-Low Emissions Transport Zone e.g. H2, V2G, Low Carbon Freight

\section{InTEGReL Future Vision}

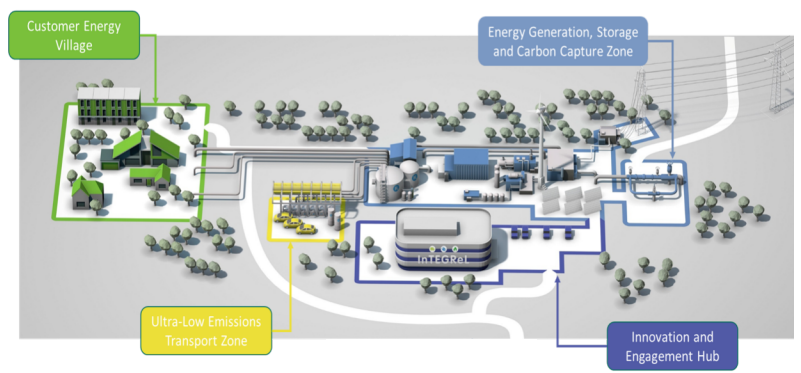

Figure 2. InTEGREL framework.

\subsection{Hydrogen Park South Australia (HyP SA)}

Hydrogen Park South Australia (HyP SA) (Figure 3 ) is an \$11.4 million demonstration project of renewable hydrogen production, storage, and supply to nearby homes via the existing gas network and to industry via tube trailers (AGN, 2020). Financial support is contributed by the Australian Gas Networks (AGN) and the South Australian Government. The facility features a 1.25 MW Siemens proton exchange membrane (PEM) electrolyser, which is the largest capacity in Australia. HyP SA decarbonises AGN's gas network as South Australia is committed to net-zero emissions by 2050 . In the initial five-year project starting in 2021, AGN will produce renewable hydrogen by water-splitting driven by electricity generated by renewable sources.

The project aims to demonstrate the feasibility of blending hydrogen into the South Australian gas network and provide necessary information to the South Australian Government for strategic plans to enhance the gas distribution network with more renewable fuel gas. The project will also show how integrating the electrolysers into the power grid can transfer more renewable electricity capacity into the grid, resulting in a higher energy stability.

Adding to this project is the recently announced agreement to supply the industry with pure hydrogen. Historically, industry in South Australia would purchase hydrogen produced from natural gas in the adjacent state of Victoria, trucking it long distances across state borders. From Quarter 1 2021, HyP SA will replace the incumbent supply and become a major industrial supplier of green hydrogen which is produced using renewable electricity at Hyp SA.

AGN is also actively working with the Australian Government and industry to deliver feasibility studies and reports through the Australian Hydrogen Centre. This work will share the knowledge and experience from HyP SA, and conduct technical feasibility studies on 100 percent hydrogen conversion of South Australia and Victoria. HyP SA was the winner of the Australian Engineering Excellence Award for South Australia in 2020.

(a)



(b)

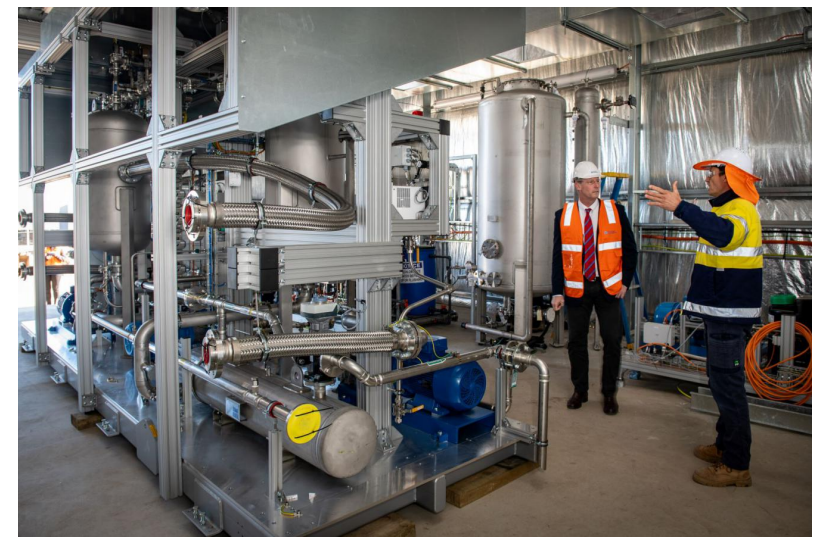

Figure 3. (a): Hydrogen Park South Australia (HyP SA); (b): The Minister of Energy of Australia visiting HyP SA.

\section{Conclusions}

Governments and private organisations around the world believe that green hydrogen produced by renewable energy can be a major alternative energy source to reduce 
the required carbon emission. Collaboration among various stakeholders including governments, regulators, industry, academia, interest groups, and media, are required to overcome the key challenges such as economic and safety regulations, funding, establishing markets, supply chain, skills and competency, and customer acceptance.

To achieve the road map towards a hydrogen economy, governments and private sectors should jointly develop precise, continuing, practical and comprehensive decarbonisation pathways for all sectors and segments. The industry should jump start the evolution from grey to blue and green hydrogen and further replace the use of fossil fuels with green hydrogen usages. Regulators should encourage blue and green hydrogen production to be accepted as renewable targets, and low carbon targets to be set across all major uses of hydrogen. To enable ultralow-carbon hydrogen to be cost-competitive with grey hydrogen, companies should ramp up their renewable electrolysis installation to commercial size to make full use of the benefits of economy of scale. At the same time, they should improve CCS (carbon capture and storage) rate and reduce capex to ensure that blue hydrogen can be produced on a large scale within the next ten years.

In the power system, regulators should support using renewable sources to run electrolysers for balancing the power system and ensuring competitive access to renewable energy. Gas companies should set decarbonisation targets for their gas grids with binding renewable contents in the gas.

The industry should position itself for capturing investment opportunities relating to the production, transportation, retail and utilisation of hydrogen. In transport, regulators should set out a clear and trustworthy road map, develop policies for zero-emission mobility with support funding and provide a guarantee to protect investment in refuelling infrastructure. The regulatory stakeholders should carry on the development of additional hydrogen power and fuel cell applications and map out to scale up the plant capacity.

Hydrogen is definitely a reliable alternate low carbon energy source for the future which has already drawn the attention of many governments and companies globally and has and will attract hundreds of billion dollars of investments along its entire value chain. In order to utilise hydrogen to help various countries to achieve the net zero target, governments should set policies to attract and safeguard investments so that the industry can have confidence to speed up commercial-scale deployment. As the Climate Change risk is imminent and severe events such as floods, wildfires, heatwaves and droughts leading to significant impact are happening more and more often, there is urgency for the whole world to act and decarbonise. The hydrogen industry will definitely enable the energy transition to establish a net-zero world.

\section{Acknowledgement}

The author would like to thank Mr Charles Chao Chung Tsai of Power Assets Holdings Limited for his valuable advice in the preparation of this paper.

\section{Notes on contributor}

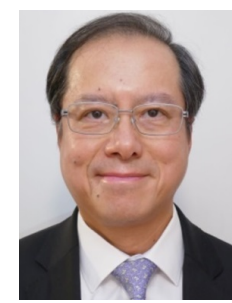

Mr Jeffrey Kwok is Senior Manager (Business Development) of Power Assets Holdings Limited and has been with the Company since September 1981. $\mathrm{He}$ is responsible for both greenfield development and acquisition activities in various countries and assumes an active management role in some of the Company's investments. He holds a Master of Science degree in Engineering and is a Chartered Engineer in the United Kingdom, a member of The Hong Kong Institution of Engineers and the Institution of Mechanical Engineers in the United Kingdom.

\section{References}

[1] Acha S, Brun N L, Damaskou M, Fubara T C, Mulgundmath V, Markides C N and Shah N (2020). Fuel cells as combined heat and power systems in commercial buildings: A case study in the food-retail sector. Energy 206 (2020), pp. 118046.

[2] AGN (2020). Hydrogen production site under construction in South Australia. Fuel Cells Bulletin, January 2020, pp. 11.

[3] Ballard Power Systems (2019). Gaoming to open as first fuel cell powered commercial tram line. Fuel Cells Bulletin, November 2019, pp. 7.

[4] Braga A H, Vidinha P and Rossi L M (2020). Hydrogenation of carbon dioxide: From waste to value. Current Opinion in Green and Sustainable Chemistry, 26, pp. 100386.

[5] BW Businessworld (2021). [Online report]. Available at: < http://www.businessworld.in/article/HydrogenWill-Play-An-Important-Role-In-A-Low-CarbonSociety-Katsuhiko-Hirose-Professional-PartnerToyota-Motor-Corporation/09-03-2018-142870/)> . [Accessed on 20 April 2021].

[6] Caglayan D C, Weber N, Heinrichs H U, Linßen J, Robinius M, Kukla P A and Stolten D (2020). Technical potential of salt caverns for hydrogen storage in Europe. International Journal of Hydrogen Energy, 45(11), pp. 6793-6805.

[7] Chrysochoidis-Antsos N, Rodr1' M R and Wijk A J M (2020). Technical potential of on-site wind powered hydrogen producing refuelling stations in the Netherlands. International Journal of Hydrogen Energy, 45(46), pp. 25096-25108. 
[8] Drift AVD, Tjeng SL, Beckers GJJ and Beesteheerde J (1996). Low-NOx hydrogen burner. International Journal of Hydrogen Energy, 21(6), pp. 445-449.

[9] Environmental and Energy Study Institute (2015). [Online] Available at: < https://www.eesi.org/articles/ view/behind-the-2-degree-scenario-presented-atcop21> [Accessed on 20 April 2021].

[10] Flynn B (2016). Marine wind energy and the North Sea Offshore Grid Initiative: A Multi-Level Perspective on a stalled technology transition?. Energy Research \& Social Science, 22, pp. 36-51.

[11] Gu Y, Chen Q, Xue J, Tang Z, Sun Y and Wu Q (2020). Comparative techno-economic study of solar energy integrated hydrogen supply pathways for hydrogen refueling stations in China. Energy Conversion and Management, 223, pp. 113240.

[12] ITM Power (2018). ITM, Northern Gas Networks report on P2G deployment study. Fuel Cells Bulletin, May 2018, pp. 11.

[13] Mohammadi A and Mehrpooya M (2018). A comprehensive review on coupling different types of electrolyzer to renewable energy sources. Energy, 158, pp. 632-655.

[14] Molkov V (2020). Hydrogen Safety Engineering and Standards, Reference Module in Earth Systems and Environmental Sciences.

[15] Nieto J, Carpintero Ó, Miguel L J (2018). Less than $2^{\circ} \mathrm{C}$ ? An Economic Environmental Evaluation of the Paris Agreement. Ecological Economics, 146, pp. 6984.

[16] Northern Gas Networks (2020). H21 Leeds City Gate Report. [online report]. Available at: $<$ https://www. h21.green/wp-content/uploads/2019/01/H21-LeedsCity-Gate-Report.pdf $>$. [Accessed on 20 April 2021].

[17] Quarton CJ and Samsatli S (2020). Should we inject hydrogen into gas grids? Practicalities and wholesystem value chain optimization., Applied Energy, 275, pp. 115172.

[18] S\&P Global Platts (2020). [online report]. Available at: < https://www.spglobal.com/platts/en/marketinsights/latest-news/electric-power/012420-fuelcell-evs-set-to-top-13-million-by-2030-as-hydrogenscales-up-hydrogen-council $>$. [Accessed on 20 April 2021].

[19] Serincan M F (2016). Validation of hybridization methodologies of fuel cell backup power systems in real-world telecom applications. International Journal of Hydrogen Energy, 41(42), pp. 19129-19140.

[20] Stern AG (2018). A new sustainable hydrogen clean energy paradigm. International Journal of Hydrogen Energy, 43(9), pp. 4244-4255.

[21] The Fuel Cells and Hydrogen Joint Undertaking (n.d). [Online report] Available at $<$ https://www.fch.europa. eu/sites/default/files/Hydrogen $\% 20$ fuel $\% 20$ cell $\% 20$ electric $\% 20$ cars. $\% 20$ The $\% 20$ clean $\% 20$ transport $\% 20$ solution.pdf). [Accessed on 20 April 2021].
[22] The World Bank (2018) [Online report] Available at < https://data.worldbank.org/indicator/EG.ELC.LOSS. ZS?end $=2014 \&$ start $=2014$. $>$ [Accessed on 20 April 2021].

[23] United States Environmental Protection Agency (n.d). [Online report] Available at < https:/www.epa.gov/ ghgemissions/global-greenhouse-gas-emissionsdata $>$. [Accessed on 20 April 2021].

[24] Wang M, Wang G, Sun Z, Zhang Y and Xu D (2019). Review of renewable energy-based hydrogen production processes for sustainable energy innovation. Global Energy Interconnection, 2(5), pp. 436-443.

[25] Weidner S, Faltenbacher M, Franc I, Thomas D, Sku'lason JB, Maggi C (2018). Feasibility study of large scale hydrogen power-togas applications and cost of the systems evolving with scaling up in Germany, Belgium and Iceland. International Journal of Hydrogen Energy, 43(33), pp. 15625-15638. 